\title{
The Use of Remotely Sensed Data for Estimating of Rice Yield Considering Soil Characteristics
}

\author{
Chiharu Hongo ${ }^{1}$, Gunardi Sigit ${ }^{2}$, Ryohei Shikata ${ }^{1}$, Katsuhisa Niwa ${ }^{3} \&$ Eisaku Tamura ${ }^{1}$ \\ ${ }^{1}$ Center for Environmental Remote Sensing, Chiba University, Chiba, Japan \\ ${ }^{2}$ Regional Office of Food Crops Service West Java Province, Indonesia, Bandung, Indonesia \\ ${ }^{3}$ Zukosha Co Ltd., Obihiro, Japan \\ Correspondence: Chiharu Hongo, Center for Environmental Remote Sensing, Chiba University, Chiba-shi \\ 263-8522, Japan Tel: 81-043-290-3859. E-mail: hongo@faculty.chiba-u.jp
}

Received: March 17, 2014 Accepted: April 24, 2014 Online Published: June 15, 2014

doi:10.5539/jas.v6n7p172 URL: http://dx.doi.org/10.5539/jas.v6n7p172

\begin{abstract}
In Indonesia, the food shortage resulting from a rapid increase in population and also the stability of food production largely affected by climate conditions have been serious problems, and it is necessary to improve a cultivation management system aiming at increasing rice yield and also the stability. The purposes of this study are to estimate the rice yield using remote sensing data and field investigation data considering soil characteristics, and also to grasp spatial distribution of the rice yield in wide area. In this study, at first, the relationship between rice yields of different soil types was examined. The soil type of each field could be classified into 3 types, according to the definition of USA soil taxonomy, which are Inceptisol, Ultisol and Entisol. Evaluation on the difference in yield among the soil types was made with the result that there was significant difference between the two: Entiso and Inceptisol. Then, the correlation between the yield and each satellite band and index was examinded about each soil type and the whole soil. As a result, both of Entisol and the whole soil showed significant correlation on all satellite bands and indexes except short-wavelength infrared, but other soil types had little correlation. This suggests that it would be better to use the whole soil without considering soil types for creating the yield estimation formula from SPOT satellite data and the ground investigated yield data. Finally, multiple linear regression analysis was conducted to develop a yield estimation formula, using the investigated rice yield data and also the reflection density of each band, NDVI, GNDVI, NDWI from SPOT satellite data of harvesting season. As a result, the estimation formula was created using NDVI and middle infrared as predictors $\left(\mathrm{r}^{2}=0.428, \mathrm{p}<0.01, \mathrm{RMSE}=0.77 \mathrm{t} / \mathrm{ha}\right)$.
\end{abstract}

Keywords: estimation of rice yield, satellite data, soil type, food security, Indonesia

\section{Introduction}

One of major concerns throughout the world is to set up the most optimal plans and measures against decrease of food production which is caused by climate change, natural disasters and other factors. According to the 4th assessment report of IPCC (Pachauri et al., 2007), a forecast on the influence over food production says that, if temperature increased only one to two degrees Celsius, the food production should decrease and risk of hunger should increase. Currently, the food security is drawing more and more attention of all people concerned.

For increase of the food production, on the other hand, one of ways to take would be, as a short cut, to expand the farming area or increase amount of fertilizers to be used, but this should not be taken up easily from view point of the conservation of agricultural ecosystem. Up to now, lots of so-called environmental friendly processes or measures suitable to the food production have been suggested, developed and introduced to many countries and farmers. But one of problems here is the fact that the farmers tend to think and act, after all, in a way that the supporting of their everyday life is more important than the considering of environmental conservation, particularly in developing countries.

Under this situation, it has been expected to develop a comprehensive system aiming to support and realize sustainable food production and the environmental conservation at the same time in the developing countries. In Indonesia, rice is one of the most important agricultural plants because rice is the staple consumed by Indonesians. 
The food security has long been an important political goal in Indonesia, and this goal is associated with rice self-sufficiency.

The middle of 1980s was the time when Indonesia had almost self-sufficient situation for rice, but from the 1990s the self-sufficiency percentage went lower due to decrease of rice production and consequential increase of import. Current level of the ratio is around 95\% for these years, although in 1998 it fell into the level of $90 \%$ because of the drought caused by the El Niño (Bappenas, 2002).

One of the measures Indonesian government did was to distribute high yield rice seed to farmers, which brought success to increase of the rice production by about 5.0\% in 2007 (David, 2010).

In order to stabilize the sefl-sufficency of rice as the important staple for Indonesia, one of the key factors to be studied is the estimation of rice production. Up to now, there are two approaches for the estimation. One is to collect rice production related information from farmers. The other is to measure the production amount in a specific area as sampling and then to calculate the total production amount in whole area based on the sampling result. These approaches are usually time and cost consuming process. Under this situation, it is expected that new approach could be developed to enable the estimation of the rice production amount with quick and inexpensive manner and also before the harvesting of rice. Remote sensing technology is one of tools to realize such new estimation approach (Xiao et al., 2005).

Concerning application of remote sensing technology for agricultural research, rice production and rice field management is especially important for Asian countries, because rice is the staple food for the people and, on the other side, Asian agriculture frequently suffers from heavy losses caused by meteorological events. Considering these matters, it is a good idea to develop an efficient rice cultivation support system based on a concept of the precision agriculture using the remote sensing technology which could effectively increase the rice production and also realize the environmental conservation.

In previous agricultural research works using remote sensing data, development of the algorithms for rice field mapping and production estimation was executed (Takezawa et al., 2007; Hongo et al., 2012; Shikata et al., 2013). One of such works conducted in Bali of Indonesia suggested that Rice Growth Vegetation Index could be a new vegetation index (Nuarsa et al., 2011a). The Index showed high correlation with rice age, and it was used to develop the algorithm for rice field distribution mapping using Landsat ETM data. The quantitative evaluation of the rice field mapping in comparison with the statistical data showed a high correlation. However, there is little information on rice yield estimation on basis of each individual rice field. Concerning relation between yield estimation and soil, it is reported that the consideration of factors such as soil conditions and farm management could increase the estimation accuracy (Paul et al., 2003) and that physical landscape such as soil types could influence over the yield of crops (Papiernik et al., 2005).

For studying the relation between yield estimation and soil at this study site, all available information was checked, but there was only the soil map in paper medium which was prepared in the 1960s, and also there was no study conducted up to now to report the relation. Under this situation, we came to decide that it would be necessary to examine the relation at the study site through analysis of soil types and characteristics and also to confirm whether different yield estimation formulas should be developed according to each soil type.

Final goal of this research is to evaluate the food availability for food security through development of the algorithm for rice yield estimation before harvesting time using remote sensing data. This is to report results of the study on relation between SPOT data, as remote sensing data, and ground truth data in order to estimate the rice yield, which can be important and valuable information for planning the adaptation measures for rice production.

\section{Study Site}

Study area is shown in the Figure 1 (long. $106^{\circ} 21^{\prime} \mathrm{E} \sim 107^{\circ} 25^{\prime} \mathrm{E}$, lat. $6^{\circ} 42^{\prime} \mathrm{N} \sim 7^{\circ} 25^{\prime} \mathrm{N}$ ), Cianjur, West Java of Indonesia. This area is one of the major rice production areas in Indonesia and is located in between Cisokan river and Citarum river from east to west both of which flow from the southern mountains down to the northern Cirata reservoir. Since this area is just under the equator with torrid climate, they have temperate climate throughout the year and also have the dry season from May to October and the rainy season from November to April. Because of this climate, harvesting is 2 to 3 times a year, and at the 3 rd time some farmers cultivate soy beans as field rotation instead of rice. In this area, with support of JICA, a large scale of irrigation system was constructed before, but there is still about $20 \%$ of rain-fed paddy field which is influenced by the change of precipitation. 


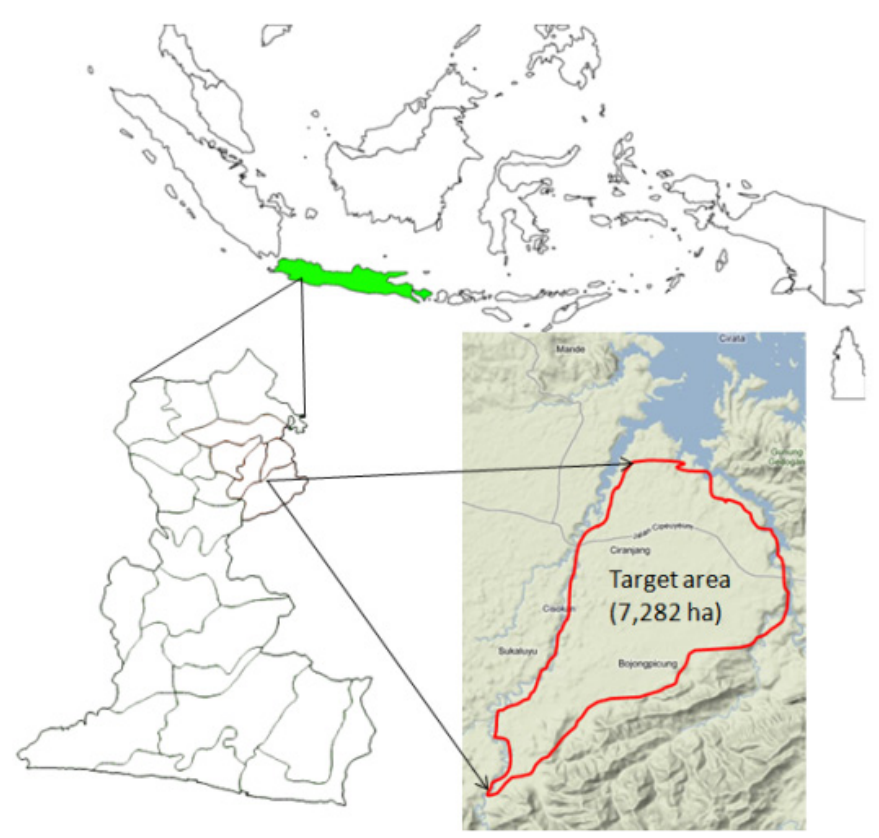

Figure 1. Study site

West Java has about $18 \%$ of the national rice production in Indonesia. Although West Java has been contributing significantly to the national production, it does not mean that rice production yield has been maximized. There is still a gap when compared with potential production yield such as shown in the Table 1 (Anonymous, 2011). From the table, it is suggested that the trend of agricultural production in West Java should be increased to meet the demands of national food needs. Even for 2012, West Java has a target of producing 12.5 million tons of rice. Opportunities to increase agricultural production in West Java are still open since there is still a big gap to the potential production. It means that there is a big opportunity to increase the production yield through development and improvement of agricultural production system in West Java.

Table 1. Differnce between actual yield and potential yield of rice, maize and soybean

\begin{tabular}{|c|c|c|c|c|c|c|}
\hline \multirow[b]{3}{*}{ Year } & \multicolumn{6}{|c|}{ Yield \& Gap } \\
\hline & \multicolumn{2}{|c|}{ Rice } & \multicolumn{2}{|c|}{ Maize } & \multicolumn{2}{|c|}{ Soybean } \\
\hline & $\begin{array}{l}\text { Yield of } \\
\text { rice } \\
\text { (ton/ha) }\end{array}$ & $\begin{array}{c}\text { Gap to it's } \\
\text { potential } \\
(7-10 \text { ton/ha)* } \\
(\%)\end{array}$ & $\begin{array}{l}\text { Yield of } \\
\text { maize } \\
\text { (ton/ha) }\end{array}$ & $\begin{array}{c}\text { Gap to it's } \\
\text { potential } \\
(7-10 \text { ton/ha)* } \\
(\%)\end{array}$ & $\begin{array}{l}\text { Yield of } \\
\text { soybean } \\
\text { (ton/ha) }\end{array}$ & $\begin{array}{c}\text { Gap to it's } \\
\text { potential } \\
(2-3.2 \text { ton/ha)* } \\
(\%)\end{array}$ \\
\hline 2006 & 5.39 & $23.0-46.1$ & 4.95 & $29.3-50.5$ & 1.37 & $31.5-57.2$ \\
\hline 2007 & 5.58 & $20.3-44.2$ & 5.09 & $27.3-49.1$ & 1.40 & $30.0-56.3$ \\
\hline 2008 & 5.77 & $17.6-42.3$ & 5.38 & $23.1-46.2$ & 1.38 & $31.0-56.9$ \\
\hline 2009 & 5.99 & $14.4-40.1$ & 5.76 & $17.7-42.4$ & 1.44 & $28.0-55.0$ \\
\hline 2010 & 5.92 & $15.4-40.8$ & 6.01 & $14.1-39.9$ & 1.52 & $24.0-52.5$ \\
\hline
\end{tabular}

* Based on the result of research center (Anonymous, 2011).

\section{Materials and Methods}

\subsection{Data for Analysis}

\subsubsection{Production Data of Rice}

From Jul 17 through 24, 2011, the investigation and sampling of rice was conducted in the study site. Selection of the specific place for the observation and sampling was made through evaluation of the difference of soil 
conditions on each candidate individual field which was just before the harvesting. The sampling was made in a way where 2 locations on the same diagonal line of each individual field were set up, and total 9 rice plants $(3 \times 3$ plants) per each location were harvested as the study sample.

The harvested rice plants were threshed and, after taking off the husk, weight of both the wet rice and the dried rice was measured. Then, based on the measured weight and the planting density of the sampling location, calculation of weight of both wet and dry matter per 1 ha was made. The numbers of investigated individual fields and investigated locations are 21 and 42, respectively. The species of cultivated rice and the number of the samples are as follows: Ciherang (14 samples), Inpari (4 samples), IR64 (2 samples), Mekonga (14 samples) and Shinta nur (6 samples).

\subsubsection{Soil Data}

For judging the soil type of each individual field, the simplified soil investigation by soil auger (classification of stratigraphic horizon, soil color, soil texture, existence of spotted patterns, depth of gravel layer, effective soil layer, etc.) and the soil profile investigation (classification of stratigraphic horizon, soil structure, existence of spotted patterns, soil hardness, soil color, soil texture, etc.) were made. In addition, the penetration resistance of each 10 $\mathrm{cm}$ depth was measured using the penetration hardness-meter in order to evaluate the following: thickness and hardness of surface soil, thickness and hardness of plow sole layer, hardness of soil under the plow sole layer. The depth of measurement made was $60 \mathrm{~cm}$ on each location except those where the meter could not penetrate into the soil due to small rocks or others.

\subsubsection{Satellite Data}

For this study, SPOT 5 data obtained on July 10, 2011 was used. There are 4 bands in the imagery, with the observation wavelengths including the green band $(500-590 \mathrm{~nm})$, red band $(610-680 \mathrm{~nm})$, near infrared band $(780-890 \mathrm{~nm})$ and short-wavelength infrared band $(1580-1750 \mathrm{~nm})$, with a $10 \mathrm{~m}$ image resolution for the visible bands and near-infrared band and a $20 \mathrm{~m}$ image resolution for the short-wavelength infrared band.

\subsection{Procedure of Rice Yield Estimation}

The satellite data was rectified with use of GIS data drawn at a scale of 1 to 25,000 through nearest neighbor resampling algorithm on the selected ground control points. At first, an image classification using cluster was executed to extract paddy fields from the satellite data. The classified paddy fields included various different growth stages of paddy field such as seedling, heading and harvesting. To extract only paddy fields ready for harvesting, the clustering method was applied to the classified paddy fields.

Secondly, the digital values of ground measurement point of paddy fields were derived from the satellite data. The evaluation of relation between SPOT data and the measured yield by soil type was made through comparison between the digital values, NDVI, GNDVI, NDWI of each investigated location, which were extracted from SPOT data, and the measured yield. The definition of NDVI, GNDVI and NDWI is as follows:

NDVI : Normalized Difference Vegetation Index $=(\mathrm{NIR}-\mathrm{R}) /(\mathrm{NIR}+\mathrm{R})$

GNDVI : Green Normalized Difference Vegetation Index $=(N I R-G) /(N I R+G)$

NDWI : Normalized Difference Water Index $=($ SWIR-R $) /(S W I R+R)$

$\mathrm{G}$ : Visible green radiation

$\mathrm{R}$ : Visible red radiation

NIR: Near infrared radiation

SWIR: Shortwave infrared radiation

To derive the rice yield estimation formula, the multiple linear regression analysis was executed using the data on digital values of visible and infrared bands, NDVI, GNDVI and NDWI. Finally, the formula was verified by 10 -fold cross validation by random data partitioning, and the predictive errors of this regression equation was derived from the estimated yield and the investigated rice yields.

\section{Results and Discussion}

\subsection{Soil Type and Physical Property}

As a result of the simplified soil investigation by soil auger, the soil profile investigation and the study of a soil map available, the soil type of each field could be classified into following 3 types (Figures 2, 3, and 4), according to the definition of USA soil taxonomy. 
(1) Inceptisol: Some area of the investigated locations is a terraced rice-field having gentle slope, and its original topography was judged as a plateau having a low pitch. In addition, since the rubble was observed, the parent material is assumed to be fluvial deposits. And, the concretion of iron was found in soil below $70 \mathrm{~cm}$ depth and, considering the fact that the concretion is usually generated after a long time oxidation-reduction reaction and no concretion exists in Entisol, the type was judged as Inceptisol. This soil type is best suitable for paddy use among the 3 types.

(2) Ultisol: Some area of the investigated locations is a terraced rice-field having steep slope, and a height above sea level is higher than that of fields of Inceptisol, which means it is located on the upper part of terrace. In the lower layer, the trace of weathering for a long time (laterization) was found and the color was red yellow, which has led to judge Ultisols as a soil type.

This type contains the least amount of organic materials in a family of the red clay where the leaching of silicate from clay has kept proceeding for a long period of time. Color is red of its own, and water is contained but it is hard.

(3) Entisol: Some area of the investigated locations is flat and a height above sea level is considered to be low. Since this area was used as paddy field, creation of crack on surface of soil section was not found and clay-like soil was observed. Considering the figures of the soil section, it is adequate to classify the area to Entisols (alluvial soil) containing fluvial deposits as parent material.

This contains low organic materials and so is considered to be alluvial soil of clay-like soil at early stage of its formation. It has strong impression of gray color and contains a lot of water.

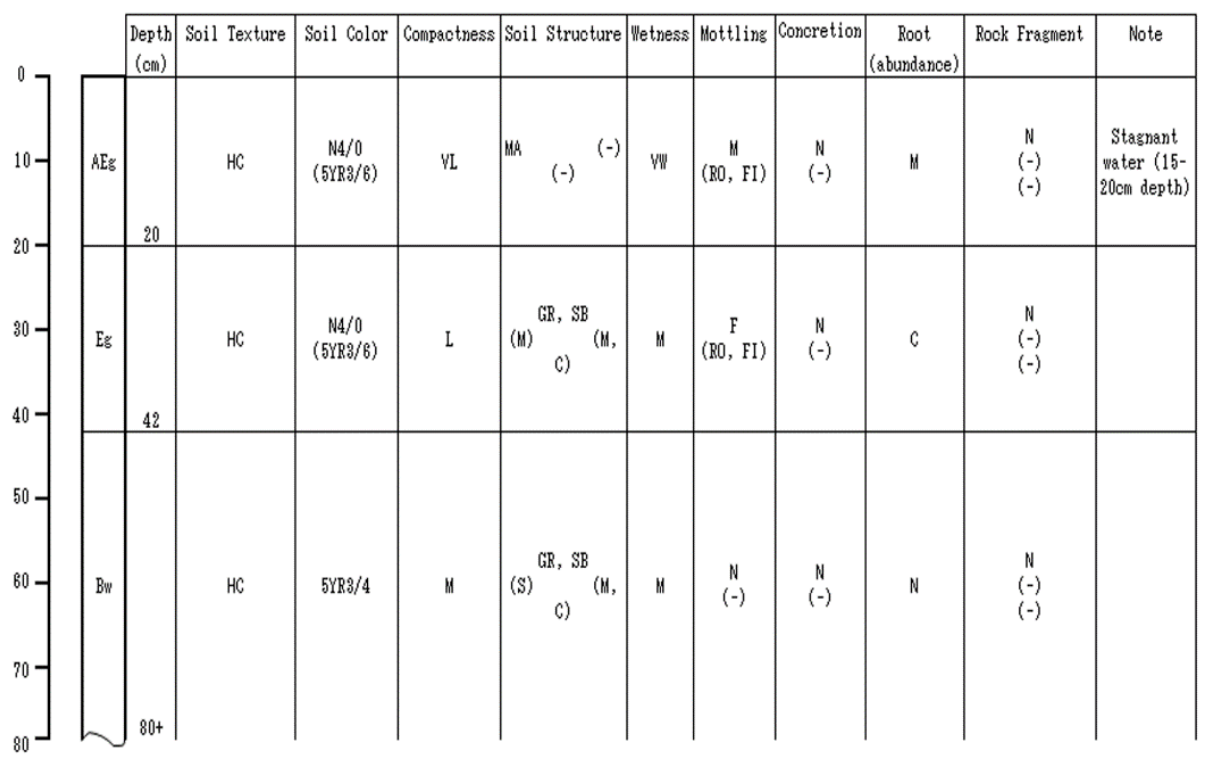

Soil texture; HC: Heavy Clay

Compactness; VL: Very Loose, L: Loose, M: Medium

Soil Structure, Type (Grade) (Size); MA (-) (-):: massive (-) (-), GR, SB (M) (M, C): Granular, Subangular blocly (Moderate) (Medium, Coarse), GR, SB (S) (M, C): Granular, Subangular blocly (Strong) (Medium, Coarse)

Wetness; VW: Very Wet, M: Moist

Mottling, Abundance (Shape); M (RO, FI): Many (Root-like, Filmy), F (RO, FI): Few (Root-like, Filmy), N (-): None (-)

Concretion, Abundance (Hardness); N (-): None (-)

Root(abundance);M:Many, C: Common, N: None

Rock Fragment, Abundance (Shape) (Size); N (-) (-): None (-) (-)

Figure 2. Physical property of Inceptisol 


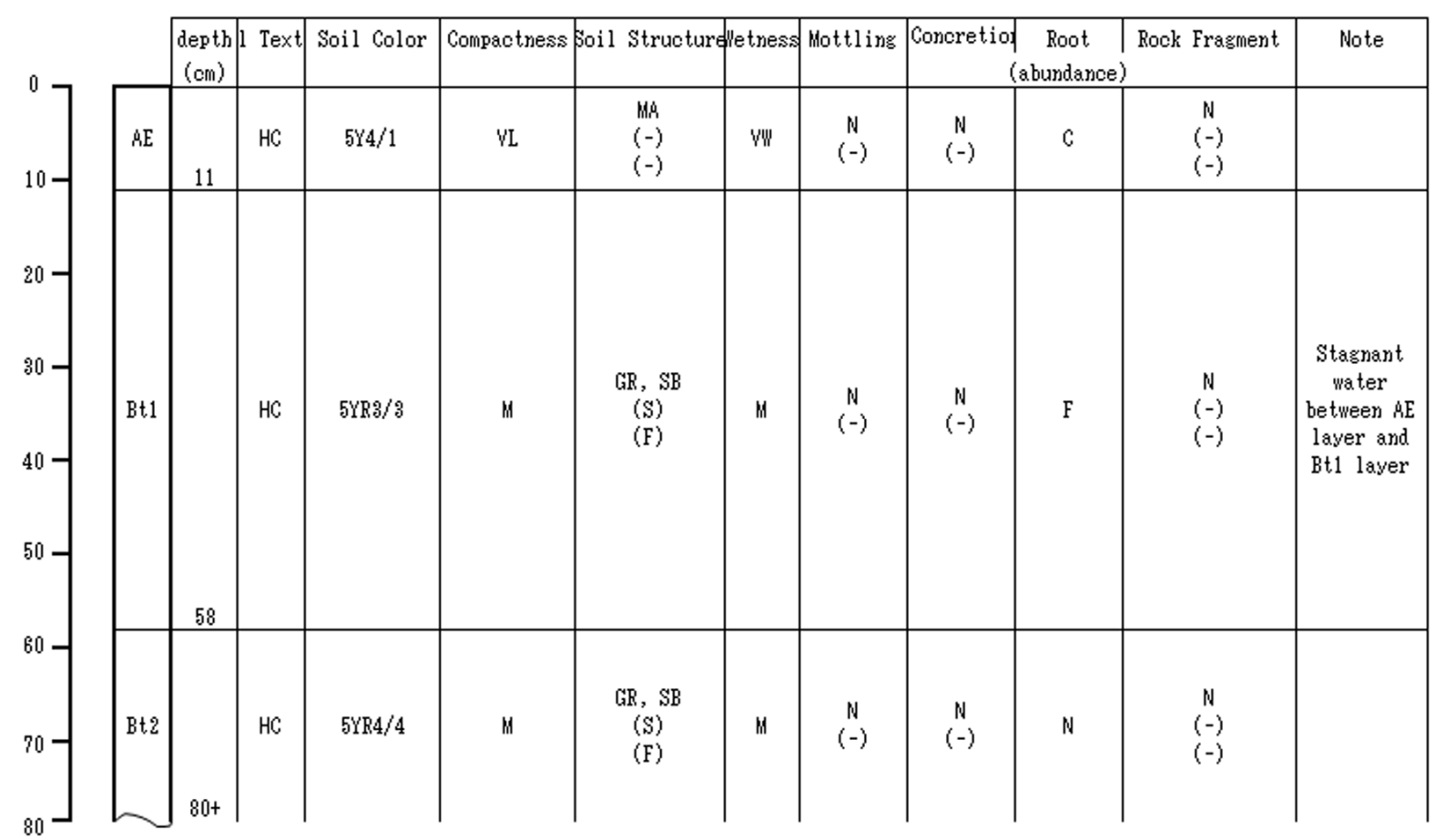

Soil texture; HC: Heavy Clay

Compactness; VL: Very Loose, L: Loose, M: Medium

Soil Structure, Type (Grade) (Size); MA (-) (-):: massive (-) (-), GR, SB (S) (F): Granular, Subangular blocly (Strong)(Fine)

Wetness; VW: Very Wet, M: Moist

Mottling, Abundance (Shape); N (-): None (-)

Concretion, Abundance (Hardness); N (-): None (-)

Root(abundance); C: Common, F: Few, N: None

Rock Fragment, Abundance (Shape) (Size); N (-) (-): None (-) (-)

Figure 3. Physical property of Ultisol 


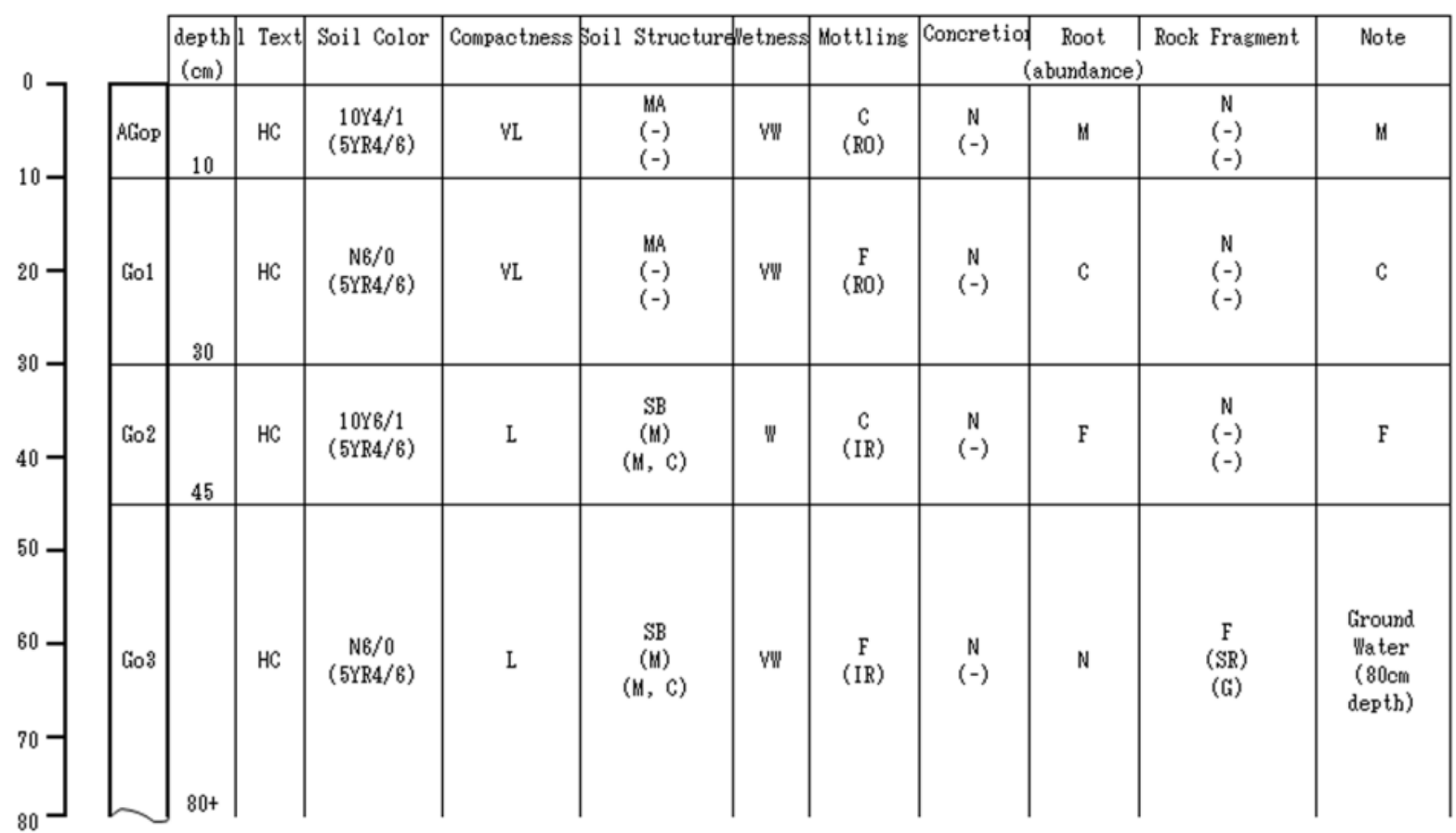

Soil texture; HC: Heavy Clay

Compactness; VL: Very Loose, L: Loose

Soil Structure, Type (Grade) (Size); MA (-) (-): Massive (-) (-), SB (M) (M, C): Subangular blocly (Moderate), (Medium, Coarse)

Wetness; VW: Very Wet, W: Wet

Mottling, Abundance (Shape); C (RO): Common (Root-like), F (RO): Few (Root-like), C (IR): Common (Irregular), F (IR): Few (Irregular)

Concretion, Abundance (Hardness); N (-): None (-)

Root(abundance);M:Many, C: Common, F: Few, N: None

Rock Fragment, Abundance (Shape) (Size); N (-) (-): None (-) (-), F (SR) (G): Few (Subrounded) (Gravel)

Figure 4. Physical property of Entisol

The penetration resistance value of soil down to $60 \mathrm{~cm}$ depth on each soil type measured by the penetration hardness-meter is shown in Figure 5. The value increases according to order of Entisol, Inceptisol and Ultisol, and also it increases according to the depth of soil about all soil types. The difference of the value between 10 $\mathrm{cm}$ depth and $20 \mathrm{~cm}$ depth is rather small on each type, but increase ratio gets bigger over $20 \mathrm{~cm}$ depth. From this result, soil from surface down to $20 \mathrm{~cm}$ is considered to be plow sole layer. Entisol is a type of soft soil having low penetration resistance value even at deep part of soil when compared with other types. Inceptisol has a limit of the penetration because of its hardness and the limit has wide variation. Ultisol is the hardest soil among the 3 types. 


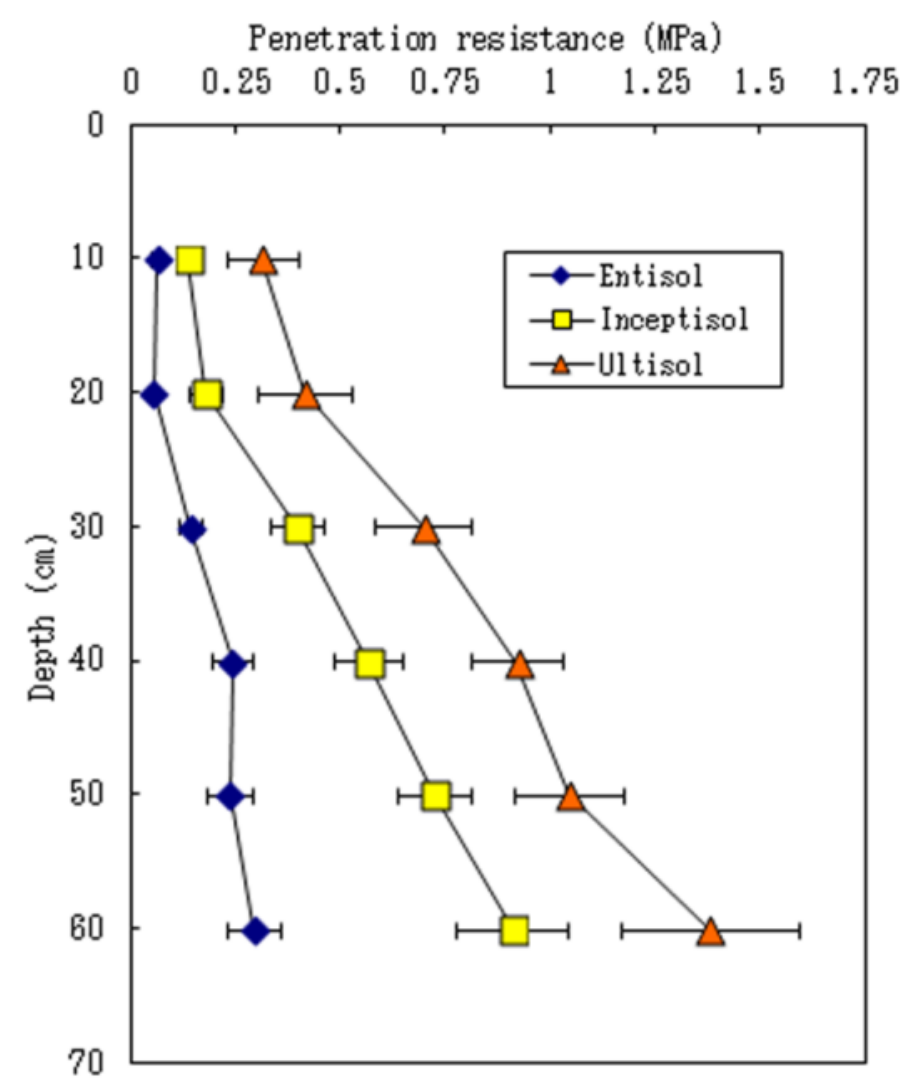

Figure 5. Penetration resistance value by each observation depth

\subsection{Relation Between Soil Characteristics and Rice Yield}

Physical property of soil and rice growth are closely related to each other as is reported that the number of rice ears decreases when surface soil gets densified and mineralization of soil nitrogen becomes difficult. The electrical conductivity of soil which is associated with physico-chemical properties is significantly related to rice production in south Asia (Ezrin et al., 2010). Therefore, the relationship between soil types and rice yield was investigated.

The average yield by soil type is shown in Figure 6. The lowest average yield is in paddy of Entisol, and Inceptisol and Ultisol have almost the same level. However, in case of Ultisol, the standard deviation of yield is relatively higher than that of others and is different according to the locations.

In case of Inceptisol which is a paddy moist all year due to improper irrigation, the soil is soft down to deep part and gives negative influence to the growth of rice root, and consequently the yield gets lower. Inceptisol, which is they say most adequate for cultivation of rice among the 3 types, the average of yield is higher than that of all others. Ultisol which is a soil having low base saturation was expected to show tendency of lower yield, but no such clear tendency was indicated due to insufficient data available at the time.

Evaluation on the difference in yield among the soil types was made with the result that there were significant differences between the two: Entiso and Inceptisol. This suggests that the soil is one of important factors giving significant influence over the yield at the study site. 


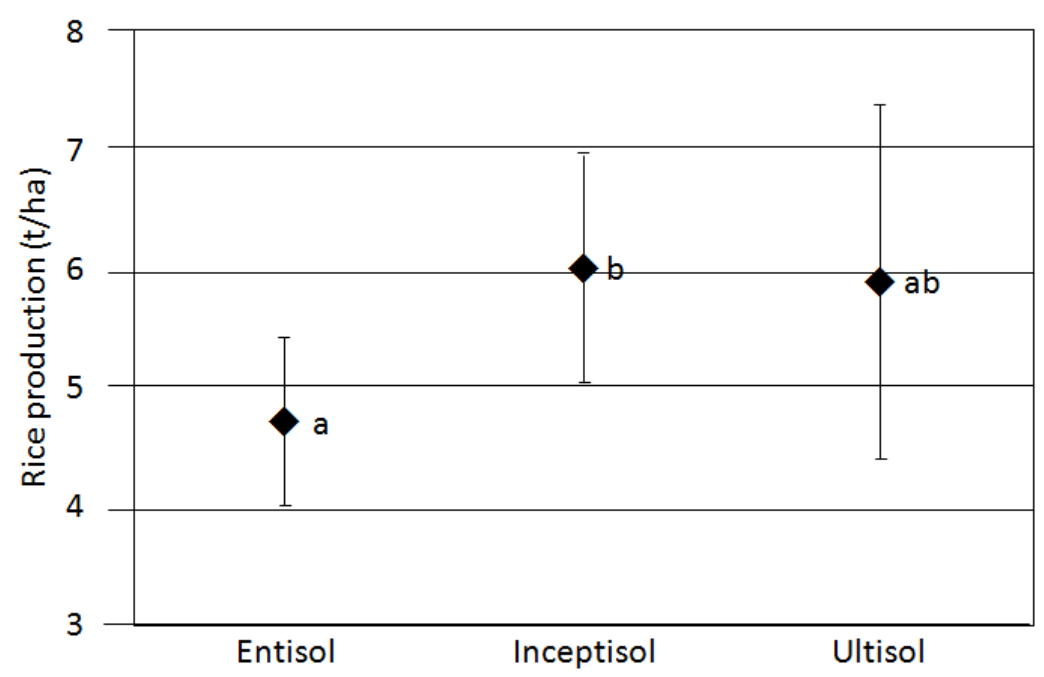

Figure 6. Average and standard deviation of yield by soil type

\subsection{Relation Between Measured Yield and Satellite Data}

The measured data on the yield ( $\mathrm{t} / \mathrm{ha}$ ) was grouped by the soil type and the relation with reflection intensity of each wavelength, NDVI, GNDVI and NDWI was studied (Table 2).

As a result, there showed significant correlation between the measured yield and the reflection intensity of green, red and near infrared wave length, NDVI, GNDVI and NDWI. By soil type, in case of Entisol, there was significant correlation on all items except the reflection intensity of middle infrared like the case of all samples. In addition, data on nitrogen fertilization and yield obtained through the hearing investigation showed significant correlation to each other.

Table 2. Correlation between each band, indexes and rice production

\begin{tabular}{lcccc}
\hline \multirow{2}{*}{ Satellite data } & \multicolumn{3}{l}{ Rice Production } \\
\cline { 2 - 5 } & All samples & Entisoil & Inceptisol & Ultisol \\
\hline Band 1 (Green) & $0.526^{* *}$ & $0.846^{* *}$ & 0.249 & 0.222 \\
Band 2(Red) & $0.605^{* *}$ & $0.885^{* *}$ & 0.263 & 0.490 \\
Band 3 (near infrared) & $0.508^{* *}$ & $0.943^{* *}$ & 0.194 & 0.585 \\
Band 4 (short-wavelength infrared) & 0.164 & 0.425 & 0.183 & 0.028 \\
NDVI & $0.595^{* *}$ & $0.954^{* *}$ & 0.223 & 0.588 \\
GNDVI & $0.598^{* *}$ & $0.939^{* *}$ & 0.226 & 0.554 \\
NDWI & $0.620^{* *}$ & $0.713^{*}$ & $0.437^{*}$ & 0.189 \\
\hline
\end{tabular}

*significant at $5 \%$ level, $* *$ significant at $1 \%$ level

\subsection{Creation of a Formula for Yield Estimation}

A formula for yield estimation was created using multiple linear regression analysis having following variables: the unit yield as response variable and 7 predictor variables including the reflection intensity of each observation wave length, NDVI, GNDVI and NDWI. Verification of the formula was made to calculate the prediction error using the ten cross validation method. Concerning the soil type, the investigation fields are divided into 3 soil types, but, since number of samples of each Entisol and Ultiso was only 8 respectively, the prediction error could not be verified, so creation of formula and prediction error were verified through combining the yields of both Entisol field and Ultisol field having the similar average yield. 
The prediction error of the estimation formula using all samples was $0.77(\mathrm{t} / \mathrm{ha})$ as shown Table 3 , which is the minimum number when compared with a case of each soil type. This means that the soil characteristics influence the rice yield at the study site, and the differnce of growth level is reflected in the reflection density level and the indexes. The result suggests that the dispersion of values of predictor variables has stretched and it would be better to use all the samples without considering soil types for creating the yield estimation formula out of satellite data.

Below is the formula of yield estimation using the whole sample. As predictor variables, the reflection density of shortwave infrared and NDVI were selected, and the coefficient of determination is $0.428(\mathrm{p}<0.01)$.

Rice yield $(\mathrm{t} / \mathrm{ha})=-4.28+0.06($ Shortwave infrared $)+11.85(\mathrm{NDVI})$

The scatter diagram of validation estimation formula is shown in Figure 7, the error of estimation was provided $0.77 \mathrm{t} /$ ha by 10 -fold cross-validation with random data partitioning.

NDVI utilizes such scientific facts that reflection value changes according to structure of leaf and the degree of overlapping of leaves and that chlorophyll in leaf has strong absorption in red wave length region. The middle infrared has an absorption band of water.

According to the estimation formula, the middle infrared is selected as a positive variable, which means that the less water content in rice plant, the more yield. This relation can be interpreted to indicate the degree of maturity of rice crop and it is said that, for a case where a rice crop has more water content due to, for example, excessive nitrogen, the yield becomes relatively lower. One more fact to support this relation is that the rice crops which grew in soil with much water showed tendency of lower yeild.As to the relation between NDVI and yield, many references report that the relation is a positive correlation (Nuarsa et al., 2011b; Nuarsa et al., 2012; Hongo et al., 2012; Jingfeng et al., 2013), and our study showed the same result.These are assumed to be a reason of selection of this index as a predictor variable.

Table 3. Prediction error and correlation of estimation formula

\begin{tabular}{lcc}
\hline & Prediction Error (t/ha) & Correlation of estimation formula \\
\hline All samples (42) & 0.77 & $0.655^{* *}$ \\
Inceptisol (26) & 1.52 & 0.437 \\
Entisoil + Ultisol (16) & 0.97 & 0.837 \\
\hline
\end{tabular}

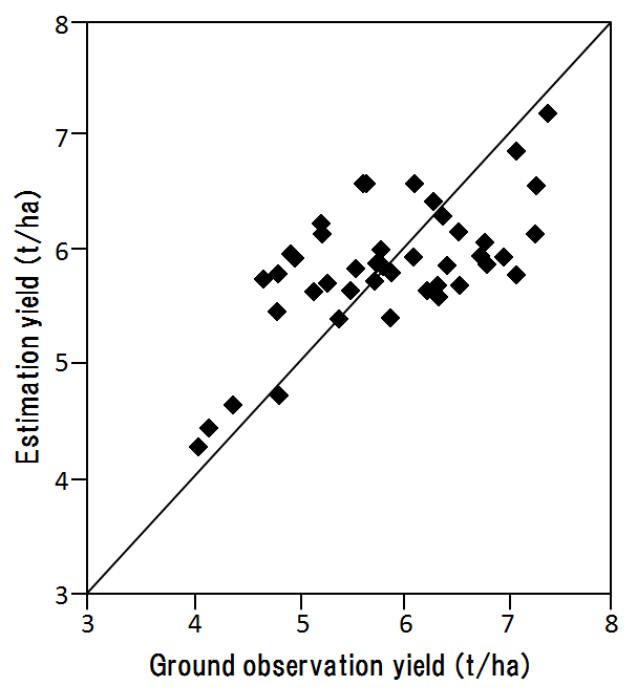

Figure 7. Prediction value by estimation formula having the leas prediction error against measured value

Figure 8 below shows a visualization map of rice yield which is generated by putting the estimation formula into each pixel of paddy field ready for harvesting. When the block plan was overlaid with the map, the dispersion of 
yield level is observed on individual field basis. According to the hearing investigation made to farmers in the study site, many of them mentioned that the supply of irrigation water seemed to be insufficient against the quantity necessary for the area. This comment is subjective and not based on the actually measured quantity, so from now we plan to conduct a study about the difference of yield between the upper stream and the down stream in the study site.

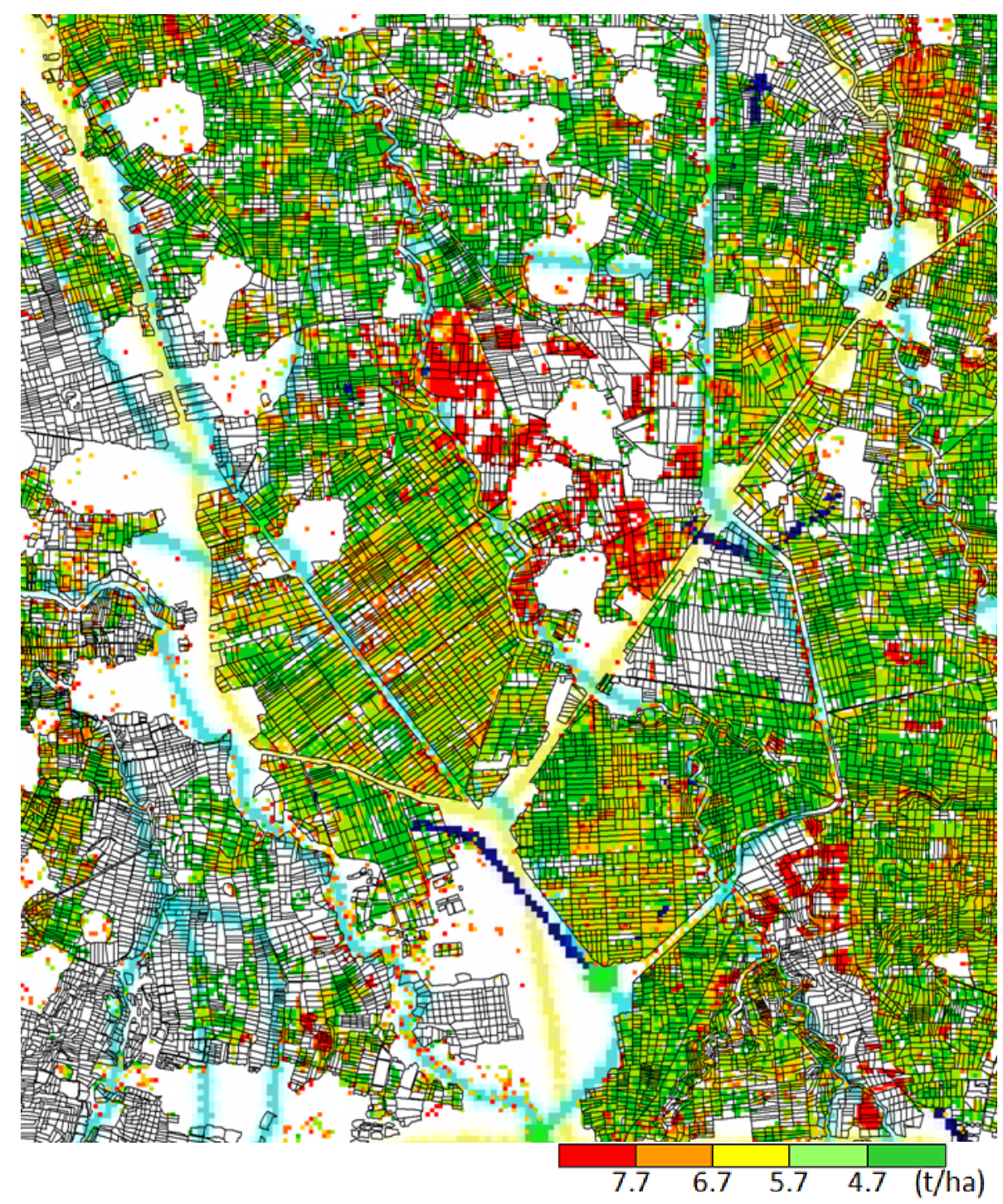

Figure 8. Map of rice yield

\section{Summary}

As a result of the soil study in Chianjur of West Java, the soil types were classified into 3 types which are Entisol、 Inceptisol and Ultisol. The measurement of penetration resistance value made it clear that in case of Inceptisol and Ultisol the soil gets harder according to depth of soil from the surface and on the other hand Entisol is rather soft soil in comparison with other types.

Evaluation of difference in yield between the soil types was made with the result that the average yield between Entisol and Inceptisol showed significant difference and indicated the influence of soil characteristics over the yield at the study site. Then, under assumption that yield estimation using satellite data could be made more accurately by soil type, multiple regression analysis was conducted. However, the result suggested that the accuracy of rice yield estimation became higher when the data was not divided by soil type and also that it was possible to estimate the yield with accuracy of prediction error at level of $0.77(\mathrm{t} / \mathrm{ha})$ using the reflection density of 
middle infrared and NDVI. Moreover through creating a map visualizing the estimation results, it became clear that the yield was different depending on fields and locations.

From standpoint of the food security, current critical issue is the increase of food production and the stable production. In developing countries such as Indonesia, the increase and the stability of food production is essential and urgent action to be taken. One of the solutions to this issue is to estimate the rice yield and also evaluate the spatial distribution of yield in a region on basis of analysis of the field survey results and utilization of remote sensing data such as analysis of satellite imagery. And the information to be obtained by such estimation and evaluation will provide important information as a base to make out adaptation plans against climate change and also could provide much of social benefit on global basis.

\section{References}

Anonymous. (2011). Data base of food crops and horticulture. Regional office of Food crops and Horticulture service, west Jawa Province (In Indonesia).

Chiharu, H., \& Katsuhisa, N. (2012b). Yield Prediction of Sugar Beet through Combined Use of Satellite Data and Meteorological Data. Journal of Agricultural Science, 4(4), 251-261. http://dx.doi.org/10.5539/jas.v4n4p251

Chiharu, H., Gunardi, S., \& Takaaki, F. (2012a). Estimation of rice yield from remotely sensed data. Proceedings of ACES and Ecosystem Markets (p. 127).

David, D. (2010). The rice crisis. FAO, 2010.

Doraiswamy, P. C., Moulin, S., Cook, P. W., \& Stern, A. (2003). Crop yield assessment from remote sensing. Photogrammetric engineering and remote sensing, 69(6), 665-674. 665674. http://dx.doi.org/10.14358/PERS.69.6.665

Ezrin, M. H., Amin, M. S. M., Anuar, A. R., \& Aimrun, W. (2010). Relationship between Rice Yield and Apparent Electrical Conductivity of Paddy Soils. American Journal of Applied Sciences, 7(1). http://dx.doi.org/10.3844/ajassp.2010.63.70

Huang, J., Wang, X., Li, X., Tian, H., \& Pan, Z. (2013). Remotely Sensed Rice Yield Prediction Using Multi-Temporal NDVI Data Derived from NOAA's-AVHRR. PloS one, 8(8), e70816. http://dx.doi.org/10.1371/journal.pone.0070816

Indonesian Food Policy Program (Bappenas). (2002). Does Indonesia Face a Food Security Time Bomb? Retrieved from http//:www.macrofoodpolicy.com

Nuarsa, I. W., Nishio, F., \& Hongo, C. (2011). Relationship between Rice Spectral and Rice Yield Using Modis Data. Journal of Agricultural Science (1916-9752), 3(2), 80-88. http://dx.doi.org/10.5539/jas.v3n2p80

Nuarsa, I. W., Nishio, F., \& Hongo, C. (2011). Spectral Characteristics and Mapping of Rice Plants Using Multi-Temporal Landsat Data. Journal of Agricultural Science (1916-9752), 3(1), 54-67.

Nuarsa, I. W., Nishio, F., \& Hongo, C. (2012). Rice Yield Estimation Using Landsat ETM+ Data and Field Observation. Journal of Agricultural Science (1916-9752), 4(3), 45-56. http://dx.doi.org/10.5539/jas.v4n3p45

Pachauri, R. K., \& Reisinger, A. (2007). IPCC Fourth Assessment Report.

Papiernik, S. K., Lindstrom, M. J., Schumacher, J. A., Farenhorst, A., Stephens, K. D., Schumacher, T. E., \& Lobb, D. A. (2005). Variation in soil properties and crop yield across an eroded prairie landscape. Journal of soil and water conservation, 60(6), 388-395.

Ryohei, S., Chiharu, H., \& Gunardi, S. (2013). Analysis of relationship between the estimated rice yield and the irrigation water system in West Java. Proceedings of The International Symposium on Remote Sensing (pp. 303-306).

Takezawa, K., Subbaiya, R. K., Seish, N., Chiharu, H., Kazuhisa, T., Akihiko, I., \& Toshiaki, T. (2007). Preliminary report on regression equations based on remote sensing data to estimate rice yield. Journal of Japanese Agricultural Systems Society, 23(2), 177-187.

Xiao, X., Boles, S., Liu, J., Zhuang, D., Frolking, S., Li, C., ... Moore, B. (2005). Mapping paddy rice agriculture in southern China using multi-temporal MODIS images. Remote Sensing of Environment, 95(4), 480-492. 480-492. http://dx.doi.org/10.1016/j.rse.2004.12.009 


\section{Copyrights}

Copyright for this article is retained by the author(s), with first publication rights granted to the journal.

This is an open-access article distributed under the terms and conditions of the Creative Commons Attribution license (http://creativecommons.org/licenses/by/3.0/). 